Electronic Supporting Information for:

\title{
Protein Design: Reengineering Cellular Retinoic Acid Binding Protein II into a Rhodopsin Protein Mimic
}

\author{
Chrysoula Vasileiou, Soheila Vaezeslami, Rachael M. Crist, Montserrat \\ Rabago-Smith, James H. Geiger*, Babak Borhan* \\ Department of Chemistry, Michigan State University, East Lansing MI 48824
}

$\begin{array}{ll}\text { MATERIALS AND METHODS } & \text { S2 }\end{array}$

GENERAL SITE-DIRECTED MUTAGENESIS PROTOCOL S2

$\begin{array}{ll}\text { PCR conditions for mutating CRABPII in pET-17b S3 } & \text { S }\end{array}$

GENERAL PROCEDURE FOR EXPRESSION OF CRABPII MUTANT PROTEINS S3

GENERAL PROCEDURE FOR THE PURIFICATION OF THE CRABPII CLONES S4

$\begin{array}{ll}\text { EXTINCTION COEFFICIENT DETERMINATION } & \text { S4 }\end{array}$

$\begin{array}{lc}\text { FLUORESCENCE TITRATIONS } & \text { S4 }\end{array}$

$\begin{array}{ll}\text { UV-VIS MEASUREMENTS } & \text { S6 }\end{array}$

GENERAL PROCEDURE FOR REDUCTIVE AMINATION OF THE PROTEIN /

RETINAL COMPLEX AND MALDI-TOF ANALYSIS $\quad$ S7

CRYSTALLIZATION AND STRUCTURE DETERMINATION

$\begin{array}{lr}\text { REFERENCES } & \text { S10 }\end{array}$ 


\section{Materials and Methods}

Fluorescence was recorded using a Fluorolog-3 (Instruments S. A., Inc.) fluorometer. UV-vis spectra were recorded with a Cary 300 Bio WinUV, Varian spectrophotometer. MALDI-TOF spectra were recorded using a Applied Biosystems Voyager STR MALDI-TOF mass spectrometer. All-trans-retinal was purchased from Fluka, and was used as received.

\section{General site-directed mutagenesis protocol}

The CRABPII-pET17b plasmid was graciously donated by Prof. H. Yan (Department of Biochemistry, Michigan State University). Site-directed mutagenesis was performed using the CRABPII-pET17b plasmid following Stratagene's Quikchange ${ }^{\circledR}$ Kit protocol. The primers used for the mutations described in the manuscript were:

- R132K (from WT-CRABPII)

Forward: 5'-GACGTTGTGTGCACCAAGGTCTACGTCCGAGAG-3'

Reverse: 5'-CTCTCGGACGTAGACCTTGGTGCACACAACGTC-3'

- R132K:Y134F (from R132K)

Forward: 5'-GTTGTGTGCACCAAGGTCTTCGTCCGAGAGCTCGAG-3'

Reverse: 5'-CTCGAGCTCTCGGACGAAGACCTTGGTGCACACAAC-3'

- R132K:Y134F:R111L (from R132K:Y134F)

Forward: 5'-CCCAAGACCTCGTGGACCCTAGAACTGACCAACGATGG-3'

Reverse: 5'-CCATCGTTGGTCAGTTCTAGGGTCCACGAGGTCTTGGG-3'

- R132K:Y134F:R111L:L121E (from R132K:Y134F:R111L)

Forward: 5'-GATGGGGAACTGATCGAGACCATGACGGCGGATGAG-3'

Reverse: 5'-CTCATCCGCCGTCATGGTCTCGATCAGTTCCCCATC-3'

- R132K:R111L:L121E (from R132K:R111L)

Forward: 5'-GATGGGGAACTGATCGAGACCATGACGGCGGATGAG-3'

Reverse: 5'-CTCATCCGCCGTCATGGTCTCGATCAGTTCCCCATC-3'

- R132K:Y134F:L121E (from R132K:Y134F)

Forward: 5'-GATGGGGAACTGATCGAGACCATGACGGCGGATGAG-3'

Reverse: 5'-CTCATCCGCCGTCATGGTCTCGATCAGTTCCCCATC-3'

- R132K:L121E (from R132K)

Forward: 5'-GATGGGGAACTGATCGAGACCATGACGGCGGATGAG-3'

Reverse: 5'-CTCATCCGCCGTCATGGTCTCGATCAGTTCCCCATC-3'

-R132K:Y134F:R111L:T54V:L121E (from R132K:Y134F:R111L:L121E)

Forward: 5'-CTACATCAAAGTCTCCACCACCGTGCG-3'

Reverse: 5'-CGCACGGTGGTGGAGACTTTGATGTAG-3'

•R132K:R111L:T54V:L121E (from R132K:R111L:L121E)

Forward: 5'-CTACATCAAAGTCTCCACCACCGTGCG-3'

Reverse: 5'-CGCACGGTGGTGGAGACTTTGATGTAG-3'

- R132K:R111L:L121Q (from R132K:R111L:L121E)

Forward: 5'-GGGGAACTGATCCAGACCATGACGGCG-3'

Reverse: 5'-CGCCGTCATGGTCTGGATCAGTTCCCC-3'

- R132L:R111L:L121E (from R132K:R111L:L121E)

Forward: 5'-GTTGTGTGCACCCTGGTCTACGTCCG-3'

Reverse: 5'-CDDACGTAGACCAGGGTGCACACAAC-3' 
PCR conditions for mutating CRABPII in pET-17b

\begin{tabular}{|c|c|c|c|}
\hline REACTANT & AMOUNT $(\mu \mathrm{L})$ & \multicolumn{2}{|c|}{ PCR Cycles } \\
\hline Template DNA $(10 \mathrm{ng} / \mu \mathrm{L})$ & 5 & $1 \mathrm{x}$ & $95^{\circ} \mathrm{C}$ for $0.5 \mathrm{~min}$ \\
\hline Primer forward (15 pmol) & a $(1-5 \mu L)$ & & $95^{\circ} \mathrm{C}$ for $0.5 \mathrm{~min}$ \\
\hline Primer reverse (15 pmol) & $\mathrm{b}(1-5 \mu \mathrm{L})$ & $16 \mathrm{x}$ & $55^{\circ} \mathrm{C}$ for $1 \mathrm{~min}$ \\
\hline pfu turbo rxn buffer (10x) & 5 & & $70{ }^{\circ} \mathrm{C}$ for $8 \mathrm{~min}$ \\
\hline$(10 \mathrm{mM})$ & 1 & $1 \mathrm{x}$ & $70{ }^{\circ} \mathrm{C}$ for $10 \mathrm{~min}$ \\
\hline Water & $50-(12+a+b)$ & $1 \mathrm{x}$ & $23^{\circ} \mathrm{C}$ for $10 \mathrm{~min}$ \\
\hline Pfu turbo polymerase & 1 & & \\
\hline
\end{tabular}

The PCR products were transfected into either JM109 or XL1-Blue competent E. coli cells for plasmid maintenance.

\section{General procedure for expression of CRABPII clones}

The target gene (CRABPII/pET17b), as isolated from the JM109/XL1-Blue cells using Qiagen's Maxi Prep ${ }^{\circledR}$ DNA isolation kit, was transformed into BL21(DE3)pLacI E. coli strain according to standard protocols and plated on Amp/Clm resistant LB plates. Typically, hundreds of colonies grew. A single colony from the plate was inoculated in LB/Amp-Clm broth (200 $\mathrm{mL}$, Amp $100 \mu \mathrm{g} / \mathrm{mL} ; \mathrm{Clm} 170 \mu \mathrm{g} / \mathrm{mL}$ ) and grown at $37^{\circ} \mathrm{C}$, while shaking, overnight. A part of the overnight culture $(50 \mathrm{~mL})$ was inoculated into $1 \mathrm{~L}$ of $\mathrm{LB} / \mathrm{Amp}-\mathrm{Clm}$ medium. The culture was incubated at $37{ }^{\circ} \mathrm{C}$ until $\mathrm{OD}_{600} \approx 0.6(\sim 3 \mathrm{~h}$ on average $)$ was reached. The expression was induced by addition of $1 \mathrm{mM}$ IPTG. The culture was incubated at $30^{\circ} \mathrm{C}$ for $6 \mathrm{~h}$. The cells were harvested by centrifugation $(6000 \mathrm{rpm}, 30 \mathrm{~min})$ and were frozen at $-20{ }^{\circ} \mathrm{C}$ overnight. The cell mass was thawed and resuspended in minimal $(20-50 \mathrm{~mL})$ buffer $(10 \mathrm{mM}$ TRIS- $\mathrm{HCl}, \mathrm{pH}=8.0$, for $4 \mathrm{~L}$ expression). The cell mass was sonicated (probe sonicator, Biologics Inc., $60 \%$ power, 3 $\mathrm{x} 1 \mathrm{~min})$, the mixture was spun down $\left(30 \mathrm{~min}, 4{ }^{\circ} \mathrm{C}, 5000 \mathrm{rpm}\right)$, and the supernatant was collected. A solution of $1 \mathrm{mM} \mathrm{MgSO}_{4}(300 \mu \mathrm{L})$ and benzonase $(30 \mu \mathrm{L}$, to reduce viscosity) was added and the mixture was incubated on ice for $30 \mathrm{~min}$. The mixture was spun down once more (6000 rpm, $30 \mathrm{~min}$ ) and the supernatant was collected for purification. 


\section{General procedure for the purification of the CRABPII mutant proteins}

The crude CRABPII supernatant was purified by ion exchange chromatography using Q Sepharose ${ }^{\mathrm{TM}}$, Fast Flow resin (Column height: $\sim 10 \mathrm{~cm}$; Diameter: $\sim 4 \mathrm{~cm}$; Binding capacity: $\sim 20$ $\mathrm{mg})$. The column was equilibrated with $10 \mathrm{mM}$ TRIS- $\mathrm{HCl}, \mathrm{pH}=8.0$ buffer $(200 \mathrm{~mL}) . \sim 1 / 3$ of a $4 \mathrm{~L}$ culture supernatant extract was loaded onto the column (usually $30 \mathrm{~mL}$ ) and $3 \mathrm{~mL}$ fractions were collected. The column was initially washed with $10 \mathrm{mM}$ TRIS- $\mathrm{HCl}, \mathrm{pH}=8.0$ buffer ( 150 $\mathrm{mL}$ ) and the protein was eluted using $10 \mathrm{mM}$ TRIS $\mathrm{HCl}, 100 \mathrm{mM} \mathrm{NaCl}, \mathrm{pH}=8.0$ buffer (100 $\mathrm{mL}$ ). The fractions containing protein were combined and concentrated and desalted by centrifugation (Millipore, Centriplus YM-10, centrifugal filter devices, $4000 \mathrm{rpm}, 5 \mathrm{~h}$ ).

The concentrated/desalted sample was dissolved in $10 \mathrm{mM}$ TRIS- $\mathrm{HCl}, \mathrm{pH}=8.0$ buffer to a final volume of $50 \mathrm{~mL}$ in order to be further purified by ion exchange chromatography (BioLogics Duo Flow, BioRad; Column: Source 15Q (quaternary ammonium strong anion exchanger); Column height: $\sim 10 \mathrm{~cm}$; Diameter: $\sim 1.5 \mathrm{~cm}$; Binding capacity: $\sim 20 \mathrm{mg}$ ). A gradient of $0-2 \mathrm{M} \mathrm{NaCl}$ in $50 \mathrm{mM}$ TRIS- $\mathrm{HCl}, \mathrm{pH}=8.0$ is used $(200 \mathrm{~mL})$. CRABPII elutes at $80 \mathrm{mM} \mathrm{NaCl}$. The purity of the protein, as analyzed by SDS-PAGE electrophoresis, is greater than $95 \%$.

\section{Extinction Coefficient Determination}

The absorption extinction coefficients $(\varepsilon)$ for the various CRABPII mutants were determined according to the method first described by Gill and von Hippel. ${ }^{1}$

\begin{tabular}{cc}
\hline Protein & $\varepsilon\left(\mathrm{M}^{-1} \mathrm{~cm}^{-1}\right)$ \\
\hline WT-CRABPII & 20,215 \\
R132K & 19,202 \\
R132K:Y134F & 18,317 \\
R132K:Y134F:R111L & 16,654 \\
R132K:Y134F:R111L:L121E & 21,500 \\
R132K:R111L:L121E & 23,131 \\
R132K:Y134F:L121E & 18,422 \\
R132K:L121E & 17,981 \\
R132K:Y134F:R111L:T54V:L121E & 19,362 \\
R132K:R111L:T54V:L121E & 19,707 \\
R132K::R111L:L121Q & 16,953 \\
R132L:R111L:L121E & 20,136 \\
\hline
\end{tabular}

\section{Fluorescence Titrations}

All samples were stored in glass containers as many plastic containers will leach fluorescent impurities into the sample. Silanized glassware was used to avoid loss of protein and a change in protein concentration. In addition, a sacrificial protein, such as gelatin, was used to 
stabilize the protein and avoid loss due to binding with the surface of the cuvette. Gelatin does not contain Trp residues, therefore it will not interfere with the fluorescence measurements.

The cuvette was allowed to sit with $3 \mathrm{~mL}$ of a $0.01 \%$ gelatin containing PBS buffer (4 $\mathrm{mM} \mathrm{NaH}_{2} \mathrm{PO}_{4}, 16 \mathrm{mM} \mathrm{Na}_{2} \mathrm{HPO}_{4}, 150 \mathrm{mM} \mathrm{NaCl}, \mathrm{pH}=7.3$ ) for 30-60 minutes. This buffer was dumped, the cuvette was rinsed once with distilled water, and the protein solution was added (3 $\mathrm{mL}, 0.5 \mu \mathrm{M})$. The sample was excited at $283 \mathrm{~nm}$ with an excitation slit width of $1.5 \mathrm{~nm}$. The fluorescence was measured at the peak maximum $(345 \mathrm{~nm})$. Retinal was added to the cuvette at varying equivalents from a $1.5 \mathrm{mM}$ stock solution in ethanol maintained in the dark. Care was taken to ensure that the EtOH volume remained below 2\%. A measurement was taken for each chromophore addition at the same wavelength. This was plotted as concentration of chromophore versus relative fluorescence intensity. The titration was complete when there was no observable quenching of fluorescence upon addition of the chromophore.

It has been reported that retinal alone (not bound in the pocket) interferes to some extend with the Trp fluorescence detection. ${ }^{2}$ Free retinal can quench some of the Trp emission while free retinoic acid does not. To correct for titrations with retinal, one must perform a blank titration with $N$-acetyltryptophanamide $(1.5 \mu \mathrm{M})$, and add back the lost fluorescence. The peak maximum for the blank is at $365 \mathrm{~nm}$.

The correction procedure for the retinal titrations involves a four-step calculation after the completion of both the protein titration and the blank titration. ${ }^{2}$

1. Determine a value of $\alpha$ for every point on the curve.

$$
\alpha=\frac{F_{\text {max }}-F}{F_{\max }-F_{o}}
$$

$F_{\max }=$ fluorescence upon saturation

$F_{o}=$ initial fluorescence

$F=$ observed fluorescence

$a=$ fraction of free binding sites

2. Determine the free ligand concentration, $\mathrm{R}$.

$$
\begin{aligned}
& R=R_{o}-n P_{o}(1-a) \\
& R_{o}=\text { ligand concentration } \\
& n=\text { number of binding sites } / \text { protein, assume } \mathrm{n}=1 \\
& P_{o}=\text { protein concentration }
\end{aligned}
$$

3. Find the fluorescence contribution of the free ligand, $F_{R}$, to be deduced from the blank $(N$-acetyltryptophanamide) titration.

4. Subtract the fluorescence contribution of the free ligand from the actual readings and plot the corrected fluorescence values vs. the ligand concentration.

$$
\left(F-F_{R}\right) \text { vs. } R_{o}
$$

5. The $\mathrm{K}_{\mathrm{d}}$ for each CRABPII mutant was determined according to the method previously described by Wang et al., ${ }^{3}$ using the fluorescence values calculated above. 


\section{$\underline{\text { UV-Vis Measurements }}$}

Solutions of CRABPII mutants $(5 \mathrm{mM})$ in PBS buffer $\left(4 \mathrm{mM} \mathrm{NaH} \mathrm{PO}_{4}, 16 \mathrm{mM}\right.$ $\left.\mathrm{Na}_{2} \mathrm{HPO}_{4}, 150 \mathrm{mM} \mathrm{NaCl}, \mathrm{pH}=7.3\right)$ were titrated with a solution of all-trans-retinal $(\varepsilon=48,000$ $\mathrm{M}^{-1} \mathrm{~cm}^{-1}, \lambda_{\max }=380 \mathrm{~nm}, \mathrm{C}=0.6 \mathrm{mM}$ ) in $\mathrm{EtOH}$ (final EtOH volume was kept less than $2 \%$ of the overall volume). Retinal was added in 0.1 equiv increments (up to 2.0 equiv) and the spectra (200-600 nm) were recorded at room temperature.

In most cases the absorption of the Schiff base chromophore overlapped with that of its protonated form. In order to tease out the correct $\lambda_{\max }$, deconvolution of the UV spectrum was performed to separate the component UV spectra. The deconvolution was performed with PeakFit (Systat Software, Inc) and for all cases an $\mathrm{R}^{2}$ of $>0.995$ was achieved. Figure S-1 illustrates the original spectrum, the component spectra and the overall fit for the R132K:Y134F:R111L: L121E:T54V CRABPII penta mutant.

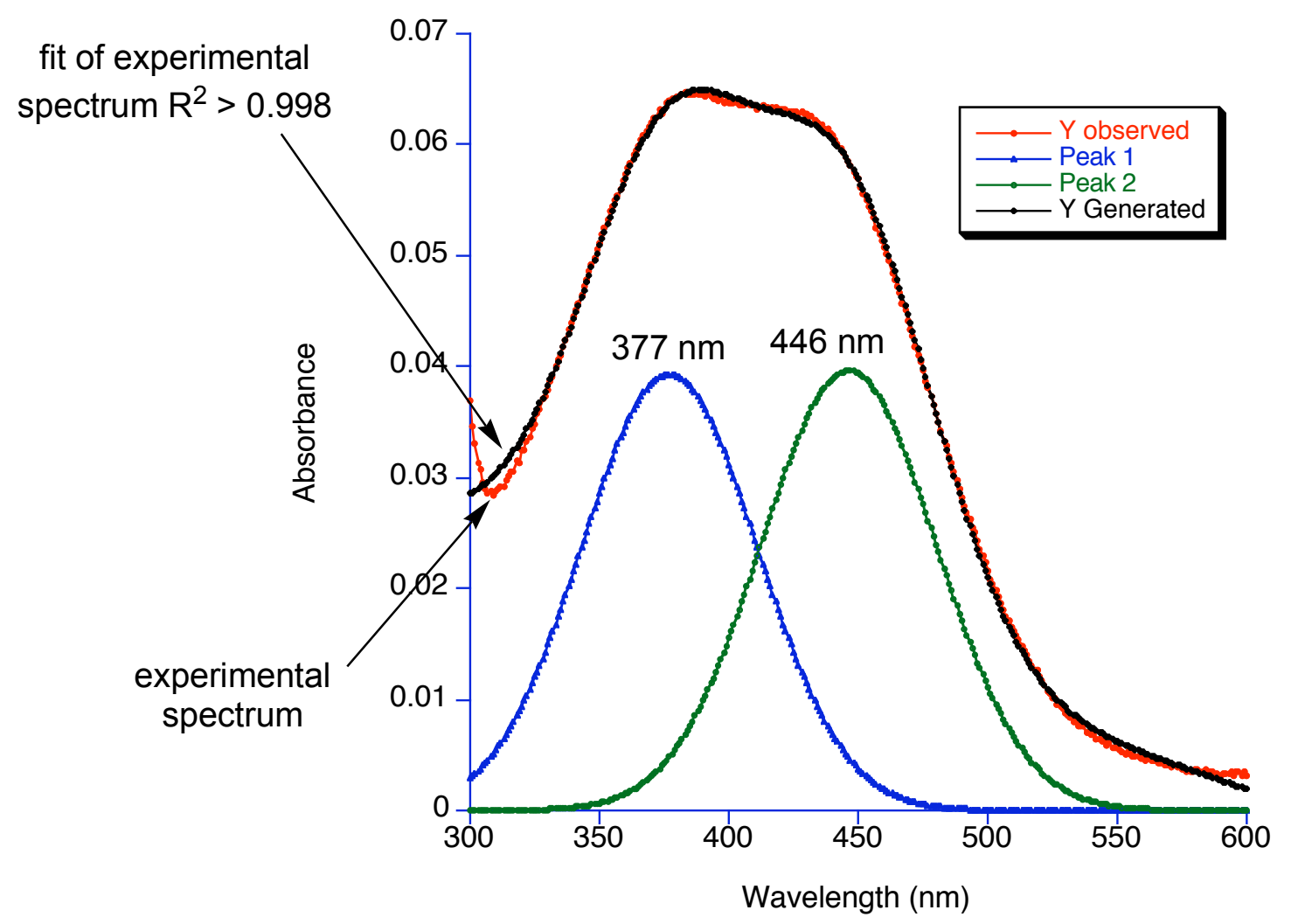

Figure S-1. The UV-vis spectrum of R132K:Y134F:R111L:L121E:T54V CRABPII penta mutant is overlaid with the fit obtained through deconvolusion with PeakFit $\left(\mathrm{R}^{2}>0.998\right)$. The component spectra are shown, clearly exhibiting an expected absorption at $377 \mathrm{~nm}$, along with the red-shifted absorption at $446 \mathrm{~nm}$, due to formation of a protonated Schiff base. 
General procedure for reductive amination of the protein / retinal complex and MALDITOF analysis

CRABPII proteins $(0.5 \mathrm{mg})$ in Tris buffer $(1 \mathrm{~mL}, 10 \mathrm{mM}$ TRIS-HCl, $\mathrm{pH}=8)$ were mixed with 1.0 equiv of retinal in ethanol (final ethanol volume less than $2 \%$ ). The mixture was incubated at $23{ }^{\circ} \mathrm{C}$, shielded from light for $1 \mathrm{~h}$ after which $10 \mu \mathrm{L}$ of $5 \mathrm{M} \mathrm{NaCNBH}_{3}$ in $1 \mathrm{~N} \mathrm{NaOH}$ was added. The reaction was incubated for an additional hour before it was applied to a $\mathrm{Q}$ Sepharose $^{\mathrm{TM}}$ Fast Flow column (quaternary ammonium resin, strong anion exchanger). The column was washed with $10 \mathrm{mM}$ TRIS $\mathrm{HCl}, \mathrm{pH}=8.0$ and the protein was eluted using $10 \mathrm{mM}$ TRIS-HCl, $100 \mathrm{mM} \mathrm{NaCl}, \mathrm{pH}=8.0$ buffer. The fractions containing protein were identified using UV-vis $\left(\mathrm{A}_{280}\right)$ and the combined fractions were concentrated to a $50 \mu \mathrm{L}$ final volume using micro-centrifuge filters (Millipore Ultrafree ${ }^{\circledR} 0.5$ Centrifugal Filters, NMWL: 5000). A small part of each reaction $(0.5 \mu \mathrm{L})$ were mixed with matrix solution $(0.5 \mu \mathrm{L})$, and upon cocrystallization, the MALDI-TOF spectrum was obtained.

\section{Typical MALDI Experimental Parameters:}

Mode of operation: Linear

Acquisition mass range: 5000 - $20000 \mathrm{Da}$

Number of laser shots: $250 /$ spectrum

Nitrogen Laser: $337 \mathrm{~nm}$

Laser intensity: 3013-3024

Laser Rep Rate: $5.2 \mathrm{~Hz}$

Calibration type: External (apomyoglobin, MW = 16952.6 Da)

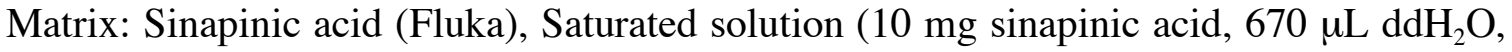
$0.3 \%$ TFA (30 $\mu \mathrm{L}, 10 \%$ solution), $30 \% \operatorname{MeCN}(300 \mu \mathrm{L})$

\section{Crystallization and structure determination:}

R132K:Y134F CRABPII/RA The complex of CRABPII with all-trans-RA was prepared fresh before each crystallization experiment, by a modified, previously published procedure. ${ }^{4}$ The protein solution $(100 \mu \mathrm{L}, 25 \mathrm{mg} / \mathrm{mL}, 1.56 \mathrm{mM})$ was diluted to a final volume of $1 \mathrm{~mL}$ with $20 \mathrm{mM}$ TRIS-HCl pH $=8.0$ buffer (final concentration of protein was $2.5 \mathrm{mg} / \mathrm{mL}$ ). RA dissolved in ethanol (10 equivalents, $156 \mu \mathrm{L}, 0.01 \mathrm{M})$ was added and the solution was reconcentrated to $\sim 25 \mathrm{mg} \mathrm{mL}^{-1}$, using Vivaspin concentrators (NMWL: 5000). Since RA is lightsensitive, all manipulations of holo-CRABPII were performed in the dark and under red light.

Crystals of R132K:Y134F bound to RA were grown by hanging drop vapor diffusion at room temperature. $2 \mu \mathrm{L}$ of the concentrated complex was mixed with an equal volume of a reservoir solution containing 20\% (w/v) PEG 5000, $0.1 \mathrm{M}$ sodium citrate/citric acid $\mathrm{pH}=4.8$, and 10\% dimethylsulphoxide (DMSO). Crystals appeared in 3 days and reached their maximum dimensions in a week. They were quick soaked in a cryoprotectant solution consisting of the reservoir solution plus 30\% glycerol and immediately frozen in liquid nitrogen. X-ray diffraction data were collected at $100{ }^{\circ} \mathrm{K}$ at the Advanced Photon Source, Structural Biology Center Beamline ID19. The structure is monomeric and has a $\mathrm{P} 2{ }_{1} 2_{1} 2_{1}$ space group with unit cell dimensions of $a=44.702 ; b=46.251, c=77.553$ as was previously obtained for the wild-type complex. ${ }^{4}$ Data was processed and scaled using the HKL suite. ${ }^{5}$ The data collection statistics are shown in Table 1. The refinement was performed using programs from the CCP4 suite 
(Collaborative Computational Project, Number 4). ${ }^{6}$ Rigid body refinement was performed using REFMAC version 5.2.0005, ${ }^{7}$ and the previously published CRABPII/RA structure (PDB entry 1CBS) as a starting model. ${ }^{8}$ The model was manually rebuilt with the program TURBOFRODO. ${ }^{9} 10 \%$ of the data was chosen randomly for cross-validation, $R_{\text {free }}{ }^{10}$ The refinement statistics are listed in Table 1.

R132K:Y134F CRABPII/RT Stability tests showed that RT is only stable for 12 hours at $25{ }^{\circ} \mathrm{C}$ in protein buffer solution but is stable for more than a week at $4{ }^{\circ} \mathrm{C}$. Therefore all crystallization experiments were performed in dark and under dark light at $4{ }^{\circ} \mathrm{C}$. Saturated RT in ethanol (12 $\mu \mathrm{L}$ of $0.055 \mathrm{M}, 4$ equivalents) was added to a purified protein solution (100 $\mu \mathrm{L}, 28$ $\mathrm{mg} / \mathrm{mL}, 1.7 \mathrm{mM}$ ) in $20 \mathrm{mM}$ TRIS- $\mathrm{HCl} \mathrm{pH}=8.0$ and the solution of protein and retinal was equilibrated for 1 hour at $4{ }^{\circ} \mathrm{C}$. This way, $\sim 12 \%(\mathrm{v} / \mathrm{v})$ of ethanol was added (we previously noticed that crystals of apo-WT-CRABPII can tolerate up to $16 \%$ (v/v) of ethanol). $2 \mu \mathrm{L}$ of this mixture was mixed with an equal volume of a reservoir solution containing 30\% (w/v) PEG 8000 and $0.2 \mathrm{M}$ ammonium sulfate. Crystals appeared in 3 days and reached their maximum dimensions in a week. Crystals were cryoprotected and frozen as described for the R132K:Y134F CRABPII/RA complex. X-ray diffraction data were collected at $100{ }^{\circ} \mathrm{K}$ at the Advanced Photon Source, COMCAT beamline 32-ID using a Mar Research 165 CCD detector. The crystals were in $\mathrm{P} 2{ }_{1} 2_{1} 2_{1}$ space group with unit cell dimensions of $a=45.493, b=46.325, c=$ 73.597. All data processing, scaling and refinement was accomplished as described for the R132K:Y134F CRABPII/RA complex. The data collection and refinement statistics are shown in Table 1.

R132K:R111L:L121E CRABPII/RT complex The protein and RT were mixed and equilibrated as described for the R132K:Y134F/RT complex. The complex of R132K:R111L:L121E with retinal was prepared by adding 4 equivalents of a saturated solution of retinal $(12 \mu \mathrm{L}$ of $0.055 \mathrm{M})$ in ethanol to the protein solution $(100 \mu \mathrm{L}$ of $27 \mathrm{mg} / \mathrm{mL}, 1.7$ $\mathrm{mM}$ ).Crystals were grown against a reservoir solution containing $0.1 \mathrm{M}$ sodium acetate $\mathrm{pH}=5.8$, $18 \%$ PEG 6000. Crystals were cryoprotected by quick-soaking in the reservoir solution plus $30 \%$ glycerol and immediately frozen in liquid nitrogen. X-ray diffraction data were collected at $100{ }^{\circ} \mathrm{K}$, at the Advanced Photon Source, COMCAT beamline (32-ID) using a Mar Research 165 CCD detector. Similar to the previous complexes crystals were in $\mathrm{P} 22_{1} 2_{1} 2_{1}$ space group with unit cell dimensions of $a=45.459, b=45.514, c=77.747$. Data was processed and the structure was refined as described previously.

Table 1

X-ray data collection and structure refinement statistics

\begin{tabular}{lll}
\hline R132K:Y134F/.RA & R132K:Y134F/.RT & R132K:R111L:L121E/.RT \\
\hline
\end{tabular}

\section{A. Data Collection}

Space group

$\mathrm{P} 2{ }_{1} 2_{1} 2_{1}$

$\mathrm{P} 2{ }_{1} 2_{1} 2_{1}$

$\mathrm{P} 2{ }_{1} 2_{1} 2_{1}$

Molecules in asymmetric unit

1

1

1 
Unit cell dimensions

\begin{tabular}{|c|c|c|c|}
\hline$a, b, c(\AA)$ & $44.70,46.25,77.55$ & $45.49,46.32,73.60$ & $45.46,45.51,77.75$ \\
\hline Wavelength $(\AA)$ & 1.00 & 1.00 & 1.00 \\
\hline Resolution range $(\AA ̊)$ & $40.0-1.70(1.76-1.70)$ & $50.0-1.69(1.75-1.69)$ & $40.00-1.18(1.22-1.18)$ \\
\hline Average $I / \sigma(I)$ & $17.66(1.91)$ & $17.03(1.74)$ & $25.60(1.68)$ \\
\hline Total reflections & 205,027 & 178,818 & 768,796 \\
\hline Unique reflections & 18,359 & 18,002 & 54,241 \\
\hline Completeness (\%) & $95.6(60.5)$ & 99.6 (99.9) & $96.7(74.6)$ \\
\hline $\mathrm{R}_{\mathrm{sym}}(\%)$ & $4.6(36.1)$ & $7.6(74.1)$ & $7.2(33.2)$ \\
\hline \multicolumn{4}{|l|}{$\begin{array}{l}\text { B. Structure } \\
\text { Refinement }\end{array}$} \\
\hline $\begin{array}{l}\text { Average B-Factor } \\
\left(\AA^{2}\right)\end{array}$ & 21.27 & 21.18 & 12.18 \\
\hline $\mathrm{R}_{\text {work }}(\%)$ & 14.50 & 15.52 & 12.85 \\
\hline $\mathrm{R}_{\text {free }}(\%)$ & 20.28 & 21.37 & 15.55 \\
\hline $\begin{array}{l}\text { Number of water } \\
\text { molecules }\end{array}$ & 187 & 153 & 250 \\
\hline Total reflections used & 17.030 & 17,868 & 52,405 \\
\hline $\begin{array}{l}\text { Total reflections in } \\
\text { work set }\end{array}$ & 15,424 & 16,053 & 49,485 \\
\hline $\begin{array}{l}\text { Total reflections in } \\
\text { test set }\end{array}$ & 1,606 & 1,815 & 2,920 \\
\hline \multicolumn{4}{|l|}{ rmsd from ideality } \\
\hline Bond lengths $(\AA)$ & 0.017 & 0.019 & 0.019 \\
\hline Bond Angles $\left({ }^{\circ}\right)$ & 1.675 & 1.819 & 1.795 \\
\hline \multicolumn{4}{|l|}{ Ramachandran plot } \\
\hline Most favored (\%) & 92.7 & 91.9 & 91.7 \\
\hline Allowed (\%) & 6.5 & 7.3 & 7.4 \\
\hline $\begin{array}{l}\text { Generously allowed } \\
(\%)\end{array}$ & 0.0 & 0.0 & 0.8 \\
\hline Disallowed (\%) & 0.8 & 0.8 & 0.0 \\
\hline PDB code & $2 \mathrm{G} 78$ & $2 G 79$ & 2G7B \\
\hline
\end{tabular}

Values in the parentheses refer to the last resolution shell. 


\section{$\underline{\text { References }}$}

(1) Gill, S. C.; Vonhippel, P. H. Analytical Biochemistry 1989, 182, 319-326.

(2) Cogan, U.; Kopelman, M.; Mokady, S.; Shinitzky, M. European Journal Of Biochemistry 1976, 65, 71-78.

(3) Wang, L. C.; Li, Y.; Yan, H. G. Journal Of Biological Chemistry 1997, 272, 1541-1547.

(4) Obergfors, T.; Kleywegt, G. J.; Jones, T. A. Acta Crystallographica Section D-Biological Crystallography 1994, 50, 370-374.

(5) Otwinowski, Z.; Minor, W. In Macromolecular Crystallography, Pt A 1997; Vol. 276, p 307-326.

(6) Bailey, S. Acta Crystallographica Section D-Biological Crystallography 1994, 50, 760763.

(7) Murshudov, G. N.; Vagin, A. A.; Dodson, E. J. Acta Crystallographica Section DBiological Crystallography 1997, 53, 240-255.

(8) Kleywegt, G. J.; Bergfors, T.; Senn, H.; Lemotte, P.; Gsell, B.; Shudo, K.; Jones, T. A. Structure 1994, 2, 1241-1258.

(9) Roussel, A.; Cambillau, C. Turbo-Frodo. Silicon graphics geometry pertners directory; Silicon Graphics, Mountain View, 1989.

(10) Brunger, A. T. Acta Crystallographica Section D-Biological Crystallography 1993, 49, 2436. 